\title{
Modeling M-phase control in Xenopus oocyte extracts: the surveillance mechanism for unreplicated DNA
}

\author{
Gabor Marlovits $^{\mathrm{a}}$, Christopher J. Tyson ${ }^{\mathrm{b}}$, Bela Novak ${ }^{\mathrm{a}, *}$, John J. Tyson ${ }^{\mathrm{b}}$ \\ ${ }^{a}$ Department of Agricultural Chemical Technology, Technical University of Budapest, Gellert ter 4, Budapest 1521, Hungary \\ ${ }^{\mathrm{b}}$ Department of Biology, Virginia Polytechnic Institute and State University, Blacksburg, VA 24061, USA
}

Revision received 15 January 1998; accepted 13 February 1998

\begin{abstract}
Alternating phases of DNA synthesis and mitosis, during the first 12 cell divisions of frog embryos, are driven by autonomous cytoplasmic oscillations of M-phase promoting factor (MPF). Cell-free extracts of frog eggs provide a convenient preparation for studying the molecular machinery that generates MPF oscillations and the surveillance mechanism that normally prevents entry into mitosis until chromosomal DNA is fully replicated. Early experiments suggested that unreplicated DNA blocks MPF activity by inducing phosphorylation of a crucial tyrosine residue, but recent evidence implicates a stoichiometric inhibitor (an MPF binding protein) as the 'braking' agent. Using a realistic mathematical model of the mitotic control system in frog egg extracts, we suggest that both tyrosine phosphorylation and a stoichiometric inhibitors are involved in the block of MPF by unreplicated DNA. Both pathways operate by raising the cyclin threshold for MPF activation. As a bonus, in the process of analyzing these experiments, we obtain more direct and reliable estimates of the rate constants in the model. (C) 1998 Elsevier Science B.V. All rights reserved
\end{abstract}

Keywords: M-phase promoting factor; Cyclin-dependent kinase; Cyclin-dependent kinase inhibitor; Wee1; Cdc25

\section{Introduction}

Immediately after fertilization, frog embryos undergo a series of rapid, synchronous cell divisions, which increase cell number and DNA content 4000fold. Unlike somatic cell cycles, which are subject to powerful controls ensuring strict alternation of DNA synthesis (S-phase) and mitosis (M-phase), early embryonic cell cycles are unfettered by these controls (surprisingly so, since mistakes are almost always fatal, for review see Ref. [1]). In particular, cytoplasmic oscillations of M-phase promoting factor (MPF),

* Corresponding author. E-mail: bnovak@chem.bme.hu the biochemical signal that drives nuclei into and out of mitosis, continue unabated in frog eggs exposed to agents that block DNA synthesis and spindle assembly [2]. Later in development, as the nucleocytoplasmic ratio increases, unreplicated DNA and unaligned chromosomes gradually exert control over MPF activation [3]. These controls can be conveniently studied in frog egg extracts by supplementing the extract with sufficient quantities of sperm nuclei in the presence of blocking agents $[4,5]$.

The embryonic cell cycle is a paradigm for oscillations and steady states in biochemical systems. The autonomous oscillations of MPF seen in early embryos surely represent limit cycle solutions to an 
underlying dynamical system governed by the molecular mechanism of MPF regulation (for review see Ref. [6]). When this cycle is halted, say, by a sufficient quantity of unreplicated DNA, the limit cycle must be replaced by a stable steady state, which is nothing other than a bifurcation in the dynamical system (perhaps a Hopf bifurcation or a saddle-node-loop) driven by parametric variation. The insertion and removal of steady states into the underlying 'cell cycle engine' is the fundamental motif for controlling proliferation of somatic cells (see, e.g. our accompanying paper in this issue). Thus, to understand the molecular mechanisms and dynamical implications of 'checkpoint controls' is an important problem in cell biology. In this paper we undertake a detailed study of the unreplicatedDNA checkpoint in frog egg extracts as an especially clear and informative example of the general problem.

\section{Model}

MPF, a crucial regulatory molecule enforcing cell cycle checkpoints, is a dimer of a cyclin-dependent protein kinase $(\mathrm{Cdc} 2)$ and cyclin B (cycB) [7]. It is regulated in three ways (for review see Ref. [8]): (1) by synthesis and degradation of its cyclin subunit, (2) by phosphorylation of $\mathrm{Cdc} 2$ on inhibitory (Thr-14, Tyr-15) and activatory (Thr-161) sites, and (3) by physical binding to inhibitory proteins called CKI's (cyclin-dependent kinase inhibitors). The checkpoint for unreplicated DNA seems to operate through phosphorylation of Tyr-15 [9] and/or through a CKI [10]. This uncertainty of the target of the signal from unreplicated DNA is the central issue addressed in this paper.

Our approach is to simulate a set of seemingly contradictory experimental results with a mathematical model of M-phase control in Xenopus based on the mechanism in Fig. 1, which is an extension of our earlier proposal [11]. Fig. 1A illustrates the reactions which manufacture active MPF. The cell synthesizes cycB from amino acids at a constant rate. Cyclins are degraded by proteasomes when they are poly-ubiquinated (for review see Ref. [12]). The rate-limiting step for degradation (described by a rate function $k_{2}$ ) is attachment of ubiquitin labels by the anaphase promoting complex (APC), called 'UbE' in our earlier model. Cyclin and $\mathrm{Cdc} 2$ monomers combine to form heterodimers, which are interconverted among four different phosphorylated states ${ }^{1}$ : unphosphorylated, Tyr-15 phosphorylated, Thr-161 phosphorylated, and doubly phosphorylated. Only the Thr-161 phosphorylated form has MPF activity. The extent of Thr161 phosphorylation is determined by CAK (Cdc2activating kinase) and a yet-uncharacterized phosphatase (for review see Ref. [13]). ${ }^{2}$ The extent of Tyr-15 phosphorylation is regulated by Wee1 and Myt1 kinases $^{3}$ (rate specified by the function $k_{\text {wee }}$ ) and by Cdc25 phosphatase (rate function $k_{c d c 25}$ ) [14-17].

Fig. 1B illustrates how MPF controls Tyr-15 phosphorylation and dephosphorylation, and ubiquitination of cyclin. Both Wee1 and Cdc25 exist in a pair of phosphorylation states: by adding phosphate groups, MPF converts Wee1 into its less active form and $\mathrm{Cdc} 25$ into its more active form $[14,16,17] .{ }^{4}$ Thus $k_{w e e}$ and $k_{c d c 25}$ are functions of MPF activity, because MPF determines the distributions of Wee1 and Cdc25 between their less active and more active forms. The influence of active MPF on Wee1 and Cdc25 creates two positive feedback circuits in the reaction mechanism, making the mitotic control system particularly sensitive to cellular conditions and decisive in its responses. As demonstrated in Novak and Tyson [11], amplification of MPF activity generated by these positive feedback loops accounts for the thresholds and lags reported by Solomon et al. [20]. In addition, periodic phosphorylation and dephosphorylation of Tyr-15, driven by these positive feedback loops,

\footnotetext{
${ }^{1}$ Because Thr-14 and Tyr-15 are phosphorylated and dephosphorylated simultaneously, we treat them as a single site, called 'Tyr-15'.

${ }^{2}$ Because Thr-161 phosphorylation occurs rapidly (half-life of unphosphorylated forms is $1 \mathrm{~min}$ ), and because the phosphatase opposing CAK is very weak, we rarely encounter large concentrations of the two Thr-161-unphosphorylated complexes.

${ }^{3}$ Since Wee1 and Myt1 collaborate in phosphorylating Cdc2 and they are similarly regulated, we lump them together as a single tyrosine kinase activity (called Wee1).

${ }^{4}$ In the model, MPF phosphorylates Wee1 and Cdc25 directly. If the effects are indirect, there would be additional time delays in the positive feedback loops. To keep the model simple, MPF is the only enzyme that phosphorylates Wee1 and Cdc25, although there is evidence for MPF-independent phosphorylation of these enzymes $[14,17,18]$. The kinase which phosphorylates Cdc25 in an MPF-independent fashion belongs to the polo kinase family [19]. Including an MPF-independent kinase activity makes no qualitative difference in the behavior of the model; it only shifts the equilibrium distribution within the dimer box in favor of active MPF.
} 

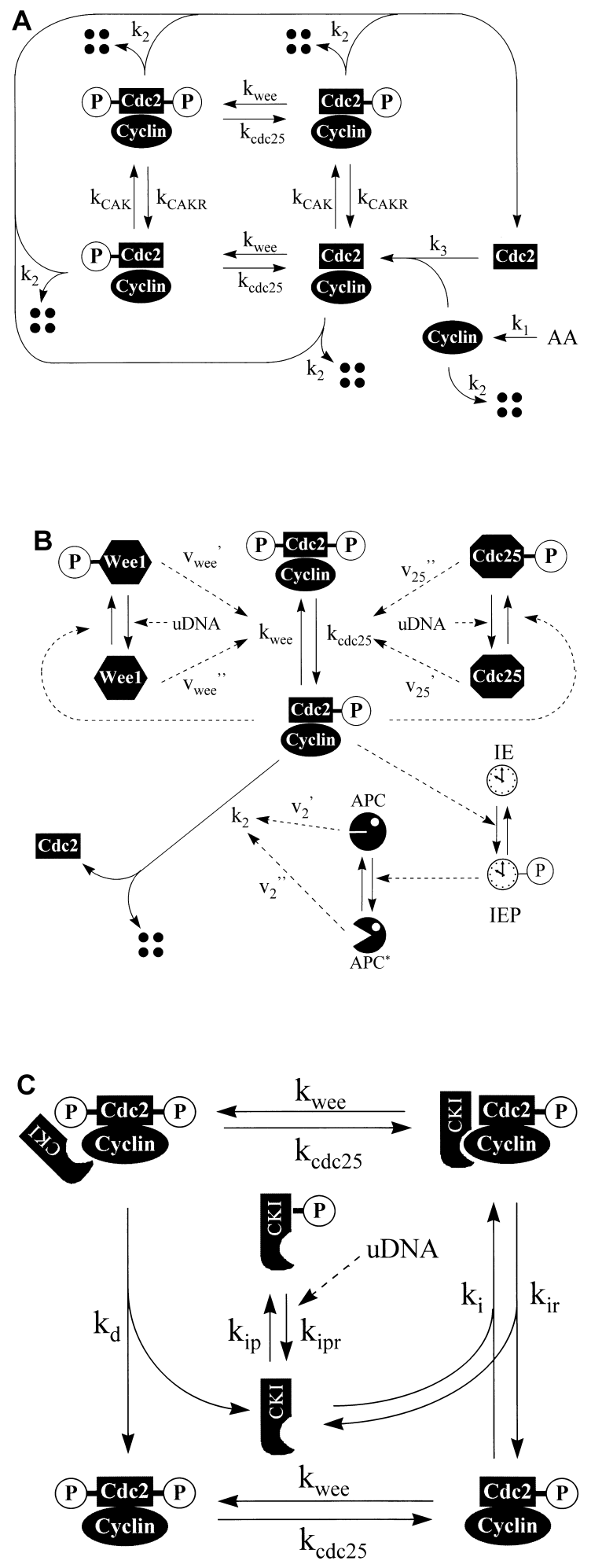

underlie oscillations in MPF activity observed in frog egg extracts [21].

In addition to activating $\mathrm{Cdc} 25$ and inhibiting Wee1, MPF also activates APC indirectly [22], through a yet unidentified intermediary enzyme (IE). Thus $k_{2}$ is also, indirectly, a function of MPF activity. High levels of MPF turn on APC, but peak APC activity lags behind peak MPF activity because IE introduces a critical time delay in the loop. This timedelayed, negative feedback loop can generate oscillations in MPF activity, driven by periodic cyclin degradation in the absence of any significant Tyr-15 phosphorylation [11,23]. Indeed, early mitotic cycles of intact embryos proceed without detectable levels of Tyr-15 phosphorylation [24].

If sufficient sperm DNA is added along with aphidicolin (an inhibitor of DNA synthesis) to a cell-free extract, then unreplicated DNA is able to block initiation of M-phase [4,9,25]. In the checkpoint-blocked extract, total cyclin level rises at the same rate as in the untreated control [4]. However $\mathrm{Cdc} 2 / \mathrm{cycB}$ dimers remain tyrosine phosphorylated (inactive), suggesting that the checkpoint signal may work through the tyrosine modifying enzymes, Wee1 and Cdc25. Smythe and Newport [26] found that tyrosine kinase activity increases 5-10-fold in the presence of unreplicated DNA. Other studies [27,28] established that activities of both type 1 and type $2 \mathrm{~A}$ phosphatases remain elevated in the presence of unreplicated DNA. Based on

Fig. 1. Molecular mechanism for M-phase control in Xenopus eggs, adapted from Ref. [11]. See text for additional details. (A) The dimer box. Newly synthesized cyclin (O)combines with $\mathrm{Cdc} 2(\square)$ to form a dimer, which is then phosphorylated on an activatory site (Thr-161, right side of Cdc2 icon) and/or on an inhibitory site (Tyr15 , left side of icon). The degradation of both free and bound cyclin subunits (step 2) is ubiquitin-mediated and is carried out by APC. When proteasomes destroy the ubiquitin-labeled cyclin subunit of a dimer, the $\mathrm{Cdc} 2$ component reverts to its free, unphosphorylated form. (B) Feedback loops. Active MPF phosphorylates Wee1 and $\mathrm{Cdc} 25$, producing a less active form of the tyrosine kinase and a more active form of the tyrosine phosphatase. Active MPF also turns on the APC indirectly, through an IE. IE introduces an important time delay in MPF-induced cyclin degradation. (C) Putative CKI. The inhibitor exists in phosphorylated ( Q-P) and unphosphorylated( $\mathrm{Q}$ )forms. Only the unphosphorylated form binds to $\mathrm{Cdc} 2 / \mathrm{cycB}$, preferentially to complexes that are not phosphorylated on Tyr-15. We show the interactions of CKI only with Thr-161phosphorylated forms; a similar box would account for transitions among the four Thr-161-unphosphorylated forms. 
these data, Novak and Tyson [11] assumed that unreplicated DNA works through the phosphatase(s) that dephosphorylates Wee1 and Cdc25. With this assumption they were able to simulate the effects of unreplicated DNA on oocyte extracts and the lengthening of cycle times as an intact embryo approaches the mid-blastula transition.

Fig. 1A,B is identical to our previous model of Xenopus mitotic controls. Recent experiments of Kumagai and Dunphy [10], to be described in detail later, will force us to extend our model to include a stoichiometric inhibitor (CKI) that binds to $\mathrm{Cdc} 2 /$ $\mathrm{CycB}$ dimers (see Fig. 1C). We assume that the inhibitor associates preferentially with Tyr-15 unphosphorylated forms and is released when the tyrosine residue gets phosphorylated. Moreover, evidence suggests that phosphorylation of the inhibitor reduces its affinity for Cdc2/cycB (see p. 208 of Ref. [10]), so we assume that phosphorylated inhibitor cannot bind to $\mathrm{Cdc} 2 / \mathrm{cycB}$ dimers. Furthermore, we assume that unreplicated DNA activates the phosphatase that removes the offending phosphate group(s) from the CKI.

Considering egg cytoplasm (or egg extract) as a uniform solution for the reactions involved in $\mathrm{M}$ phase control, we translate the mechanism of Fig. $1 \mathrm{~A}-\mathrm{C}$ into the system of differential equations in Table 1 using the law of mass action. Our simulations are carried out with a basal set of parameter values given in Table 2. How these parameter values are estimated is described in the Appendix. Notice that the rate constants characterizing certain key phosphatases $\left(k_{\mathrm{ipr}}, k_{25 \mathrm{r}}, k_{\mathrm{wr}}\right)$ are increased in the presence of unreplicated DNA, accounting for its ability to inhibit MPF activation.

\section{Autonomous MPF oscillations and the cyclin threshold}

Given the parameter values in Table 2, our mathematical model generates a free-running oscillation of cyclin synthesis and degradation and of Tyr-15 phosphorylation and dephosphorylation (Fig. 2), reminiscent of in vitro MPF oscillations in Xenopus extracts $[4,21]$. Fig. 2 also shows how the regulatory enzymes, Wee1 and Cdc25, fluctuate during the endogenous cycle. Notice that, in interphase, Wee1 never gets fully activated and Cdc25 never gets fully inactivated, because there is always enough MPF to maintain some phosphorylation of these enzymes. Nonetheless, the Wee1:Cdc25 ratio during interphase is sufficient to maintain the increasing number of $\mathrm{Cdc} 2 / \mathrm{cycB}$ dimers in inactive (Tyr-15 phosphorylated) forms, until the total amount of cyclin B, distributed among the four dimer forms, exceeds a definite threshold. When the cyclin threshold is reached, enough dimers are in the active form to trigger the positive feedback loops: inactivating Wee1 and activating Cdc25. The resultant autocatalytic rise in MPF activity drives nuclei in the extract into mitosis, and then, after a time lag, activates the APC, which degrades cyclins and drives the extract back into interphase.

The 'cyclin threshold', which is critical to understanding MPF oscillations in Xenopus egg extracts, is best demonstrated experimentally [20] and theoretically [11] in cycloheximide-arrested interphase extracts (no cyclin synthesis) supplemented with exogenously prepared, non-degradable cyclin. Simulating such experiments with our basal parameter values, we find a sharp cyclin threshold for MPF activation: 16 nM non-degradable cyclin cannot activate MPF, but $17 \mathrm{nM}$ does, although only after a long lag period (Fig. 3 ). (This threshold value was set by adjusting some of the parameters in the model, as described in Appendix A). With degradable cyclin the threshold is slightly larger $(23 \mathrm{nM})$. For cyclin levels well above threshold, the model shows a lag of about 10 min (Fig. 3), in good agreement with experiments [20,29]. Since we did not use the lag time to determine any rate constants in our model, this agreement with experiments is gratifying.

\section{Effect of unreplicated DNA on Wee1 and Cdc25}

To model the checkpoint for unreplicated DNA, we assumed in our previous model that incomplete DNA replication activates a signal transduction pathway that ultimately dephosphorylates both Wee1 (favoring its active form) and $\mathrm{Cdc} 25$ (favoring its inactive form). These changes keep $\mathrm{Cdc} 2 / \mathrm{cycB}$ in its inactive, tyrosine-phosphorylated form. Recently, Kumagai and Dunphy [10] used a non-degradable cyclin B as a substrate to assay tyrosine kinase activity in a mitotic extract and in interphase extracts with or without 
Table 1

Differential equations

Cyclin monomer and Cdc2/cyclin dimers synthesis and degradation

$1 \cdot \frac{d}{d t}[\mathrm{O}]=\mathrm{k}_{1}-[\mathrm{O}]\left(\mathrm{k}_{2}+\mathrm{k}_{3}[\square]\right)$

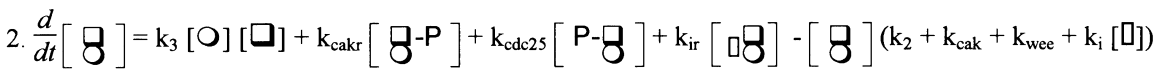

$3 \cdot \frac{d}{d t}[\mathrm{P}-\mathrm{g}]=\mathrm{k}_{\mathrm{cakr}}[\mathrm{P}-\mathrm{g}-\mathrm{P}]+\mathrm{k}_{\mathrm{wee}}[\boldsymbol{\delta}]+\mathrm{k}_{\mathrm{d}}[\mathrm{P} \boldsymbol{\mathrm { P }}]-[\mathrm{P}-\mathrm{g}]\left(\mathrm{k}_{2}+\mathrm{k}_{\mathrm{cak}}+\mathrm{k}_{\mathrm{cdc25}}\right)$

4. $\frac{d}{d t}[\mathrm{P}-\mathrm{g}-\mathrm{P}]=\mathrm{k}_{\mathrm{cak}}[\mathrm{P}-\mathrm{g}]+\mathrm{k}_{\mathrm{wee}}[\mathrm{g}-\mathrm{P}]+\mathrm{k}_{\mathrm{d}}[\mathrm{P} \mathrm{Q}-\mathrm{P}]-[\mathrm{P}-\mathrm{g}-\mathrm{P}]\left(\mathrm{k}_{2}+\mathrm{k}_{\mathrm{cakr}}+\mathrm{k}_{\mathrm{cdc25}}\right)$

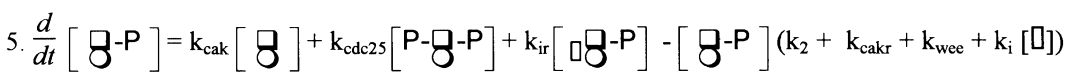

Interconversion of $\mathrm{Cdc} 2 /$ cyclin B/inhibitor complexes

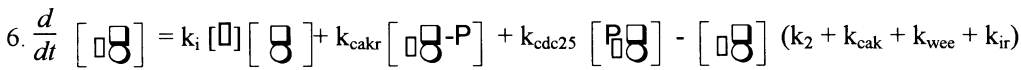

7. $\frac{d}{d t}[\mathrm{P} 8]=\mathrm{k}_{\mathrm{cakr}}[\mathrm{P} \delta-\mathrm{P}]+\mathrm{k}_{\mathrm{wee}}[\mathrm{Q} \Omega]-[\mathrm{P} /]\left(\mathrm{k}_{2}+\mathrm{k}_{\mathrm{cak}}+\mathrm{k}_{\mathrm{cdc} 25}+\mathrm{k}_{\mathrm{d}}\right)$

8. $\frac{d}{d t}[\mathrm{P} 8-\mathrm{P}]=\mathrm{k}_{\mathrm{cak}}[\mathrm{P} 8]+\mathrm{k}_{\mathrm{wee}}[\mathrm{Q} 8-\mathrm{P}]-[\mathrm{P} 8-\mathrm{P}]\left(\mathrm{k}_{2}+\mathrm{k}_{\mathrm{cakr}}+\mathrm{k}_{\mathrm{cdc25}}+\mathrm{k}_{\mathrm{d}}\right)$

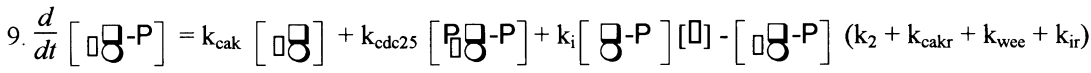

Inhibitor phosphorylation and inactivation

10. $\frac{d}{d t}[\mathrm{D}-\mathrm{P}]=\mathrm{k}_{\mathrm{ip}}[\mathrm{\square}]-\mathrm{k}_{\mathrm{ipr}}[\mathrm{D}-\mathrm{P}]$

Tyrosine phosphorylating/dephosphorylating enzymes

11. $\frac{d}{d t}[\mathrm{Cdc} 25 \mathrm{P}]=\frac{\mathrm{k}_{25}[\mathrm{MPF}][\mathrm{Cdc} 25]}{\mathrm{K}_{\mathrm{m} 25}+[\mathrm{Cdc} 25]}-\frac{\mathrm{k}_{25 \mathrm{r}}[\mathrm{Cdc} 25 \mathrm{P}]}{\mathrm{K}_{\mathrm{m} 25 \mathrm{r}}+[\mathrm{Cdc} 25 \mathrm{P}]}$

12. $\frac{d}{d t}[\mathrm{Wee}]=-\frac{\mathrm{k}_{\mathrm{w}}[\mathrm{MPF}][\mathrm{Wee}]}{\mathrm{K}_{\mathrm{mw}}+[\mathrm{Wee}]}+\frac{\mathrm{k}_{\mathrm{wr}}[\mathrm{WeeP}]}{\mathrm{K}_{\mathrm{mwr}}+[\mathrm{WeeP}]}$

Cyclin degradation pathway

13. $\frac{d}{d t}[\mathrm{IEP}]=\frac{\mathrm{k}_{\mathrm{ie}}[\mathrm{MPF}][\mathrm{IE}]}{\mathrm{K}_{\mathrm{mie}}+[\mathrm{IE}]}-\frac{\mathrm{k}_{\mathrm{ier}}[\mathrm{IEP}]}{\mathrm{K}_{\mathrm{mier}}+[\mathrm{IEP}]}$

14. $\frac{d}{d t}\left[\mathrm{APC}^{*}\right]=\frac{\mathrm{k}_{\mathrm{ap}}[\mathrm{IEP}][\mathrm{APC}]}{\mathrm{K}_{\mathrm{map}}+[\mathrm{APC}]}-\frac{\mathrm{k}_{\mathrm{apr}}\left[\mathrm{APC}^{*}\right]}{\mathrm{K}_{\mathrm{mapr}}+\left[\mathrm{APC}^{*}\right]}$ 
Table 1 (continued)

Differential equations

Lamin phosphorylation and NEB

15. $\frac{d}{d t}[\mathrm{LamP}]=\mathrm{k}_{\mathrm{lam}}\left[\nabla^{-\mathrm{P}}\right]\left([\mathrm{Lam}]_{\mathrm{total}}-[\mathrm{LamP}]\right)$

16. $\mathrm{NEB}=100 \% * \frac{[\mathrm{LamP}]-\mathrm{z}}{[\mathrm{Lam}]_{\text {total }}-\mathrm{z}} * \operatorname{Heav}\left(\frac{[\text { LamP }]-\mathrm{z}}{[\text { Lam }]_{\text {total }}-\mathrm{z}}\right)$

Rate functions

17. $\mathrm{k}_{2}=\mathrm{V}_{2}^{\prime}[\mathrm{APC}]+\mathrm{V}_{2}{ }^{\prime \prime}\left[\mathrm{APC}^{*}\right]$

18. $\mathrm{k}_{\mathrm{cdc} 25}=\mathrm{V}_{25}{ }^{\prime}[\mathrm{Cdc} 25]+\mathrm{V}_{25}{ }^{\prime}[\mathrm{Cdc} 25 \mathrm{P}]$

19. $\mathrm{k}_{\text {wee }}=\mathrm{V}_{\text {wee }}{ }^{\prime}[\mathrm{WeeP}]+\mathrm{V}_{\text {wee }}{ }^{\prime \prime}[\mathrm{Wee}]$

Conservation equations

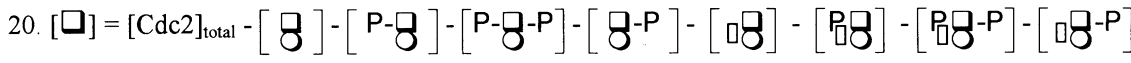

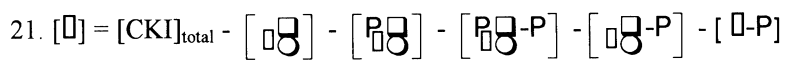

$$
\begin{aligned}
& \text { 22. }[\mathrm{Cdc} 25]=[\mathrm{Cdc} 25]_{\text {total }}-[\mathrm{Cdc} 25 \mathrm{P}] \\
& \text { 23. }[\mathrm{WeeP}]=[\mathrm{Wee}]_{\mathrm{total}}-[\mathrm{Wee}] \\
& \text { 24. }[\mathrm{IE}]=[\mathrm{IE}]_{\mathrm{total}}-[\mathrm{IEP}] \\
& \text { 25. }[\mathrm{APC}]=[\mathrm{APC}]_{\text {total }}-\left[\mathrm{APC}^{*}\right]
\end{aligned}
$$

Eqs. (1)-(5) describe cyclin synthesis and degradation, dimer formation and dimer interconversion. In the differential equations cyclin, Cdc2 and CKI are represented by $\mathrm{O}, \square$ and $\mathrm{Q}$, respectively. We write no differential equation for [Cdc2] because the total endogenous concentration of $\mathrm{Cdc} 2$ protein (in free and complex forms), [Cdc2 $]_{\text {total }}$, remains constant during the cell cycle. Thus [Cdc2] is given by Eq. (20). We also assume that total inhibitor concentration $[\mathrm{CKI}]_{\text {total }}$ stays constant, so the free inhibitor concentration can be calculated by Eq. (21). The total endogenous concentrations of Cdc25, Wee1, IE, and APC also remain constant on the time scale of Xenopus extract experiments. At any given time, these totals are split between the more and less active forms of the molecules (Eqs. (22)-(25)). Michaelis-Menten rate laws for the (more) active form of each appear as Eqs. (11)-(14). In Eqs. (17)-(19), for the variable rate factors $k_{2}, k_{c d c 25}$, and $k_{\text {wee }}$, the turnover numbers $V_{\mathrm{i}}^{\prime \prime}$ and $V_{\mathrm{i}}^{\prime}$ correspond respectively to the more and less active forms of the enzyme. To describe the experiments of Kumagai and Dunphy [10] monitoring nuclear envelope breakdown, we assume that NEB occurs after a threshold fraction of lamins on the nuclear envelope are phosphorylated by MPF [42,43]. This assumption is described by Eqs. (15) and (16). The heaviside function $(\operatorname{Heav}(x)=0$ if $x<0,=1$ if $x \geq 0$ ) holds NEB at $0 \%$ until [LamP] exceeds $z$, a threshold fraction of [Lam $]_{\text {total. }}$. Then the nuclear envelope breaks down as a linear function of [LamP], reaching $100 \%$ when the lamins are entirely phosphorylated.

unreplicated DNA. ${ }^{5}$ Their data (see Fig. 4) clearly show that tyrosine kinase activity depends on the cell cycle stage of the extract: high in interphase and low in M-phase. However, the initial accumulation of the tyrosine phosphorylated forms in the interphase extracts was indistinguishable whether the 

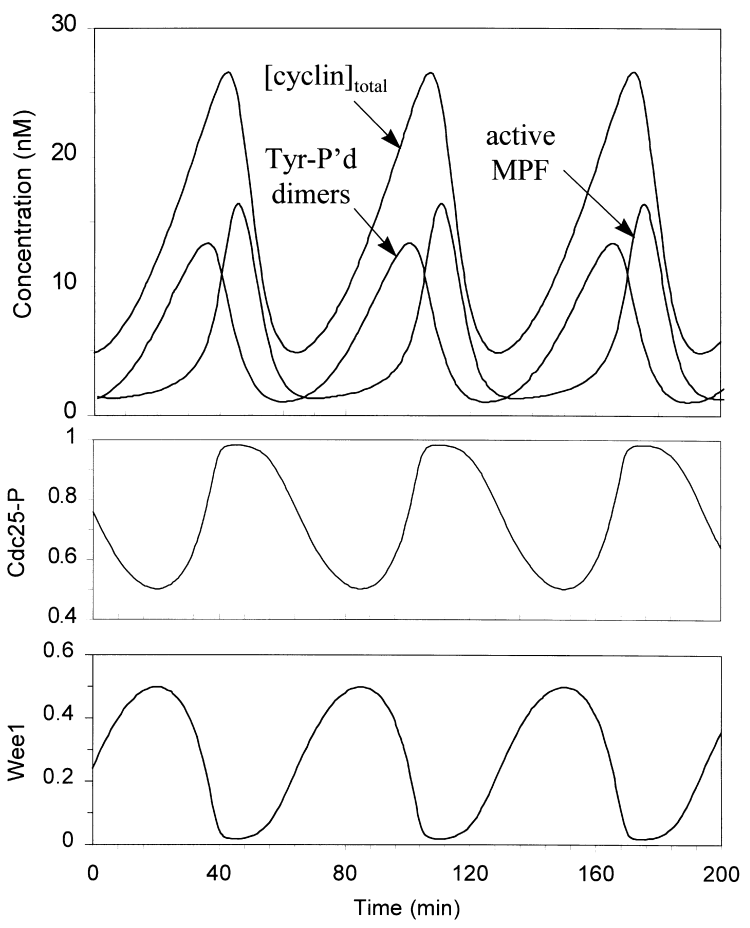

Fig. 2. Spontaneous oscillations in a cell-free extract. Simulation: basal parameter values, except $[\mathrm{CKI}]_{\text {total }}=0$, because no nuclei are added to the extract. (All simulations were carried out in PhasePlane [41], using Gear's method of integration.) The oscillation has a period of $65 \mathrm{~min}$. Cyclin is synthesized at a constant rate $\left(k_{1}=1\right.$ $\left.\mathrm{nM} \mathrm{min}{ }^{-1}\right)$ and gets degraded abruptly at the end of mitosis. Dimers accumulate primarily in the doubly phosphorylated form until total cyclin level exceeds the cyclin threshold $(23 \mathrm{nM})$, after which they are activated by dephosphorylating the Tyr-15 site. On the two lower panels, Cdc25-P and Wee1 refer to the fraction of total enzyme in the active form.

extract was checkpoint-arrested or not. Based on these results they concluded that Weel activity was unaffected by unreplicated DNA. Intuitively, these results argue against involvement of Wee1 in the DNA checkpoint, but we want to show, by model simulations, that the observations of Kumagai and Dunphy are consistent with our assumption that unreplicated DNA activates the phosphatase that dephosphorylates Wee1 and Cdc25.

\footnotetext{
${ }^{5}$ The 'interphase' extracts used by Kumagai and Dunphy [10] contain cycloheximide, an inhibitor of protein synthesis. Because the extract cannot synthesize endogenous cyclin B, it cannot proceed into mitosis. MPF activity in an interphase extract is vanishingly small. A 'mitotic' extract is arrested with high MPF activity by CSF (cytostatic factor).
}

Table 2

Parameter values

\begin{tabular}{|c|c|c|}
\hline Parameter & Numerical value & Notes \\
\hline$[\mathrm{Cdc} 2]_{\text {total }}$ & $100 \mathrm{nM}$ & [20], p. 1022 \\
\hline \multicolumn{3}{|l|}{ Cyclin synthesis } \\
\hline$k_{1}$ & $1 \mathrm{nM} \mathrm{min}-1$ & [10], Fig. 10 \\
\hline$k_{3}$ & $0.005 \mathrm{nM}^{-1} \min ^{-1}$ & [10], Fig. 3 \\
\hline \multicolumn{3}{|c|}{ Thr-161 phosphorylation and dephosphorylation } \\
\hline$k_{c a k}$ & $0.64 \mathrm{~min}^{-1}$ & [10], Fig. 5B \\
\hline$k_{\text {cakr }}$ & $0.004 \mathrm{~min}^{-1}$ & [10], Fig. 6; [36], Fig. 5 \\
\hline \multicolumn{3}{|c|}{ Tyr-15 phosphorylation and dephosphorylation } \\
\hline$V_{\text {wee }}[\mathrm{Wee} 1]_{\text {total }}$ & $0.01 \mathrm{~min}^{-1}$ & [38], Fig. 5 \\
\hline$V_{\text {wee }}{ }^{\prime \prime}[\mathrm{Wee} 1]_{\text {total }}$ & $1 \mathrm{~min}^{-1}$ & [10], Fig. 2C Fig. 3C \\
\hline$V_{25}^{\prime \prime}[\mathrm{Cdc} 25]_{\text {total }}$ & $0.017 \mathrm{~min}^{-1}$ & [10], Fig. 4B; [36] \\
\hline$V_{25}{ }^{\prime \prime}[\mathrm{Cdc} 25]_{\text {total }}$ & $0.17 \mathrm{~min}^{-1}$ & [10], Fig. 4B; [36] \\
\hline \multicolumn{3}{|c|}{ Weel phosphorylation and dephosphorylation } \\
\hline$k_{\mathrm{w}} /[\text { Wee } 1]_{\text {total }}$ & $0.02 \mathrm{nM}^{-1} \min ^{-1}$ & [38], Fig. 2 \\
\hline \multirow[t]{2}{*}{$k_{\mathrm{wr}} /[\mathrm{Wee} 1]_{\text {total }}$} & $0.1 \mathrm{~min}^{-1}$ & $\begin{array}{l}\text { In the absence of } \\
\text { unreplicated DNA }\end{array}$ \\
\hline & $0.3-0.8 \mathrm{~min}^{-1}$ & $\begin{array}{l}\text { In the presence of } \\
\text { unreplicated DNA }\end{array}$ \\
\hline$K_{\mathrm{mw}} /[\mathrm{Wee} 1]_{\mathrm{total}}$ & 0.1 & \\
\hline$K_{\mathrm{mwr}} /[\mathrm{Wee} 1]_{\mathrm{total}}$ & 1 & \\
\hline \multicolumn{3}{|c|}{ Cdc25 phosphorylation and dephosphorylation } \\
\hline$k_{25} /[\mathrm{Cdc} 25]_{\text {total }}$ & $0.02 \mathrm{nM}^{-1} \min ^{-1}$ & [17], Fig. 10A \\
\hline \multirow[t]{2}{*}{$k_{25 \mathrm{r}} /[\mathrm{Cdc} 25]_{\text {total }}$} & $0.1 \mathrm{~min}^{-1}$ & $\begin{array}{l}\text { In the absence of } \\
\text { unreplicated DNA }\end{array}$ \\
\hline & $0.3-0.8 \mathrm{~min}^{-1}$ & $\begin{array}{l}\text { In the presence of } \\
\text { unreplicated DNA }\end{array}$ \\
\hline$K_{\mathrm{m} 25} /[\mathrm{Cdc} 25]_{\text {total }}$ & 0.1 & \\
\hline$K_{\mathrm{m} 25 \mathrm{r}} /[\mathrm{Cdc} 25]_{\text {total }}$ & 1 & \\
\hline \multicolumn{3}{|c|}{ Cyclin degradation pathway } \\
\hline$V_{2}^{\prime}[\mathrm{APC}]_{\text {total }}$ & $0.005 \mathrm{~min}^{-1}$ & [40], Fig. 7 \\
\hline$V_{2}^{\prime \prime}[\mathrm{APC}]_{\text {total }}$ & $0.25 \mathrm{~min}^{-1}$ & [22], Fig. 1A \\
\hline$k_{\mathrm{ie}} /[\mathrm{IE}]_{\mathrm{total}}$ & $0.02 \mathrm{nM}^{-1} \min ^{-1}$ & \\
\hline$k_{\text {ier }} /[\mathrm{IE}]_{\text {total }}$ & $0.15 \min ^{-1}$ & \\
\hline$K_{\text {mie }} /[\text { IE }]_{\text {total }}$ & 0.01 & \\
\hline$K_{\text {mier }} /[\mathrm{IE}]_{\text {total }}$ & 0.01 & \\
\hline$k_{\mathrm{ap}}[\mathrm{IE}]_{\mathrm{total}} /[\mathrm{APC}]_{\mathrm{total}}$ & $0.13 \mathrm{~min}^{-1}$ & [22], Fig. 1A \\
\hline$k_{\text {apr }} /[\mathrm{APC}]_{\text {total }}$ & $0.13 \mathrm{~min}^{-1}$ & \\
\hline$K_{\text {map }} /[\mathrm{APC}]_{\text {total }}$ & 0.01 & \\
\hline$K_{\text {mapr }} /[\mathrm{APC}]_{\text {total }}$ & 1 & \\
\hline \multicolumn{3}{|c|}{ Inhibitor binding and phosphorylation } \\
\hline$[\mathrm{CKI}]_{\text {total }}$ & $3.5 \mathrm{nM}$ & \\
\hline$k_{\mathrm{i}}$ & $0.5 \mathrm{nM}^{-1} \min ^{-1}$ & \\
\hline$k_{\text {ir }}$ & $0.01 \mathrm{~min}^{-1}$ & \\
\hline$k_{\mathrm{d}}$ & $1 \mathrm{~min}^{-1}$ & \\
\hline$k_{\text {ip }}$ & $0.05 \min ^{-1}$ & \\
\hline \multirow[t]{2}{*}{$\begin{array}{l}n_{\text {1p }} \\
k_{\text {ipr }}\end{array}$} & $0.001 \min ^{-1}$ & $\begin{array}{l}\text { In the absence of } \\
\text { unreplicated DNA }\end{array}$ \\
\hline & $0.05 \mathrm{~min}^{-1}$ & $\begin{array}{l}\text { In the presence of } \\
\text { unreplicated DNA }\end{array}$ \\
\hline \multicolumn{3}{|c|}{ Lamin phosphorylation and NEB } \\
\hline$k_{\mathrm{lam}}$ & $0.007 \mathrm{nM}^{-1} \min ^{-1}$ & \\
\hline$z /[\text { Lam }]_{\text {total }}$ & 0.8 & \\
\hline
\end{tabular}




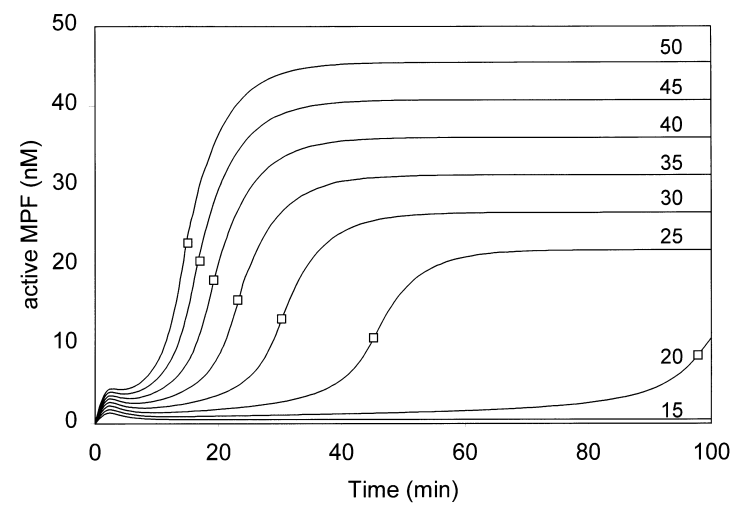

Fig. 3. Cyclin threshold for MPF activation in cycloheximideblocked extracts supplemented with exogenous, non-degradable cyclin. Simulations of the model equations in Table 1, with parameter values in Table 2, except $[\mathrm{CKI}]=0$ (no inhibitor) and $k_{1}=V_{2}^{\prime}=V_{2}^{\prime \prime}=0$. Each curve is labeled by the amount of added cyclin (nM). Open squares indicate the 'lag time', i.e. the time elapsed from cyclin addition until MPF activity reaches one-half its asymptotic value.

Fig. 4 shows a simulation of Kumagai and Dunphy's [10] experiments along with the original data from their Fig. 3B. In interphase extracts, the rapidly formed $\mathrm{Cdc} 2 / \mathrm{cycB}$ dimers get almost completely tyrosine phosphorylated during the first $10 \mathrm{~min}$, according to our simulation. Unreplicated DNA has no effect on the rate of tyrosine phosphorylation, even though we elevated 3-fold the activity of the phosphatases working on Wee1 and Cdc25 ( $k_{\mathrm{wr}}=k_{25 \mathrm{r}}=0.3$ instead of 0.1 ). The reason is that Wee1 is already in its active form at the beginning of the experiment, since cyclin synthesis was blocked by cycloheximide and there is no MPF activity in these extracts to inactivate Wee1. As a consequence, both interphase extracts start to phosphorylate Tyr- 15 of $\mathrm{Cdc} 2 / \mathrm{cycB}$ dimers with the same (maximal) rate. Unreplicated DNA does not increase the rate of tyrosine phosphorylation, but rather keeps it at the maximal level. Differences between the two extracts can be seen only later, when the checkpoint-arrested extract will keep the dimers tyrosine phosphorylated, whereas an extract without unreplicated DNA will dephosphorylate the dimers and activate MPF in an autocatalytic fashion. This difference arises because unreplicated DNA increases the cyclin threshold of the positive feedback loop by activating the phosphatase(s) working on the tyrosine-modifying enzymes. If the cyclin threshold is raised above the maximum attainable level of $\mathrm{Cdc} 2 /$
cycB dimers, then the extract (or cell) becomes arrested in interphase.

In contrast to the results of Kumagai and Dunphy [10], Smythe and Newport [26] found an elevated tyrosine kinase activity when unreplicated DNA was added to a cycling extract (not arrested by cycloheximide, as in the experiments of Kumagai and Dunphy [10]). Smythe and Newport [26] assayed Wee1 activity by adding a large excess of GST-cyclin (a nondegradable recombinant protein consisting of the glutathione-binding domain of glutathione $S$-transferase fused to residues $13-401$ of sea urchin cyclin B1) together with $0.5 \mathrm{mM}$ vanadate (an inhibitor of tyrosine phosphatases); after a $10 \mathrm{~min}$ incubation, $\mathrm{Cdc} 2 /$ GST-cyclin dimers were recovered by immunoprecipitation and the phosphotyrosine content of $\mathrm{Cdc} 2$ was measured.

Fig. 5 shows our simulation (continuous line) of Smythe and Newport's experiment [26] (their Fig. 2)

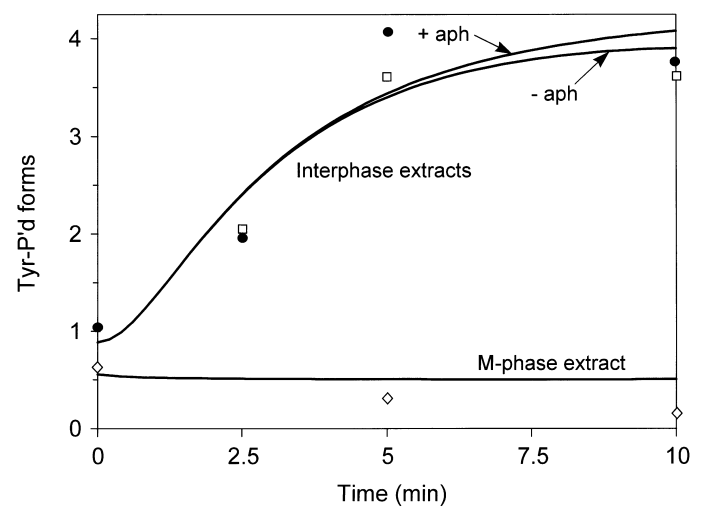

Fig. 4. Unreplicated DNA does not activate Wee1 in interphasearrested extracts. Data from Fig. 3B of Ref. [10]: $32 \mathrm{nM}$ nondegradable $\Delta$ cycB was added to M-phase extracts $(\diamond)$ and to interphase extracts with no nuclei $(\square,-$ aph) and with 1000 nuclei/ $\mu$ l plus $100 \mu \mathrm{g} / \mathrm{ml}$ aphidicolin $(\bullet,+\mathrm{aph})$, and tyrosine-phosphorylated complexes were quantified by anti-phosphotyrosine antibody (arbitrary units). Simulation: $[\mathrm{CKI}]_{\text {total }}=0, k_{1}=0$ (interphase ex-tract), $V_{2}^{\prime}=V_{2}^{\prime \prime}=0$ (M-phase extract), $k_{\mathrm{wr}}=k_{25 \mathrm{r}}=0.3 \mathrm{~min}^{-1}$ (in presence of unreplicated DNA). We assumed that interphase extracts contained some tyrosine-phosphorylated dimers at $t=0$, as indicated by the data: since there was no MPF activity at $t=0$, Wee 1 was active and $\operatorname{Cdc} 25$ inactive. The mitotic extract had some tyrosinephosphorylated dimers at $t=0$ and a sufficient quantity of active MPF to inactivate Wee1 and activate Cdc25. Notice that, whether unreplicated DNA is present or not, the rate of Tyr- 15 phosphorylation in interphase extracts is comparable. (In this and the following figures, open symbols $(\square)$ denote extracts without unreplicated DNA and filled symbols $(\bullet)$ denote extracts containing unreplicated DNA.) 
in which they measured the rate of tyrosine phosphorylation in extracts containing 500 nuclei/ $\mu$ l (no aphidicolin added). Under these conditions, the extract cycles between interphase and mitosis, replicating the sperm DNA, and the rate of tyrosine phosphorylation is elevated during interphase and reduced during mitosis. Up to this point there is no contradiction with the Kumagai and Dunphy's [10] data.

However, Smythe and Newport ([26], see their Fig. 4) found in cycling extracts that the activity of Wee1 is 5-10-fold higher in the presence of unreplicated DNA (500 nuclei/ $\mu$ l plus aphidicolin) than without it (no nuclei). The contradictory results of Kumagai and Dunphy [10] and Smythe and Newport [26] can be attributed to the different extracts in which they assayed for Wee1 activity. Wee1 and MPF are antagonistic protein kinases: each inhibits the other by phosphorylation. Therefore they tend to exclude one another: either Wee1 is active and MPF not, or vice versa. A cycloheximide-arrested extract, as used by Kumagai and Dunphy [10], has low MPF activity and high Wee1 activity. Treating a cycloheximide-arrested extract with unreplicated DNA, one can see no further increase in Wee1 activity, because the enzyme is already fully activated. Smythe and Newport [26], on the other hand, used a nuclei-free cycling extract, for which Wee1 never gets fully activated because it is in competition with endogenous MPF (see Fig. 2). As new $\mathrm{Cdc} 2 /$ cyclin dimers form after addition of excess GST-cyclin, the balance between Wee1 and MPF in the extract is upset. In the ensuing competition (Fig. 6A), MPF wins: Wee1 is turned off before the $\mathrm{Cdc} 2 /$ GST-cyclin dimers can be significantly Tyr-phosphorylated. On the other hand, in the checkpointarrested extract (Fig. 6B), Wee1 is fully activated in response to the unreplicated DNA. Given this 'head start' over MPF, Wee1 now wins the competition: Wee1 remains highly active, rapidly phosphorylating Cdc2/GST-cyclin on Tyr-15, before the dimers can inactivate Wee1.

According to our model, unreplicated DNA increases the activity of phosphatases working on Wee1 and Cdc25, thereby increasing the cyclin threshold. This is indicated in our simulation of the Smythe and Newport [26] experiment: in the checkpoint-arrested extract (Fig. 6B), total dimer level rises above $70 \mathrm{nM}$ with no sign that Wee1 will turn off.

Kumagai and Dunphy [10] have also investigated the effects of unreplicated DNA on the activity of $\mathrm{Cdc} 25$. They found the rate of dephosphorylation of ${ }^{32} \mathrm{P}$-labeled $\mathrm{Cdc} 2 / \mathrm{cycB}$ complexes to be high in mitotic and low in interphase extracts, and they could detect no change in total $\mathrm{Cdc} 25$ tyrosine phosphatase activity in interphase extracts in the presence of unreplicated DNA. However, our simulations (not shown) demonstrate that their data are also consistent with our model in which unreplicated DNA activates the phosphatase which keeps Cdc25 in the less active form.

Although there are no differences in the initial activities of Wee1 and Cdc25 in interphase extracts in the presence or absence of unreplicated DNA, the final outcome is very different (Fig. 7). In the absence of unreplicated DNA, H1 kinase activity rises and the nuclear envelope breaks down. In the presence of unreplicated DNA, H1 kinase activity remains low and nuclear envelope breakdown (NEB) does not occur.

\section{Evidence for a CKI activated by unreplicated DNA}

Up to this point we have accounted for all these

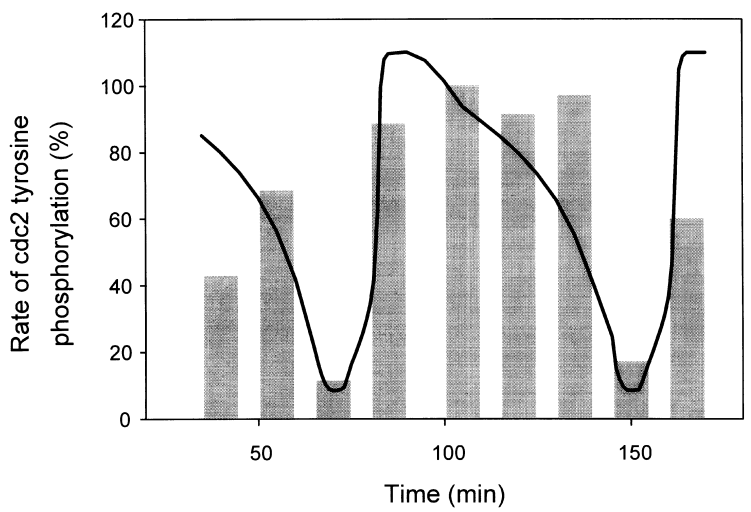

Fig. 5. Tyrosine kinase activity fluctuates in cycling extracts $(500$ nuclei $/ \mu 1$, no aphidicolin, no cycloheximide). Data (bars) from Fig. 2 of Ref. [26]: tyrosine kinase activity was determined by measuring the accumulation of phosphotyrosine on $\mathrm{Cdc} 2$ during a $10 \mathrm{~min}$ interval after addition of excess GST-cyclin and vanadate (to inhibit tyrosine phosphatase activity). Simulation: $[\mathrm{CKI}]_{\text {total }}=0, k_{1}=1$ $\mathrm{nM} \min ^{-1}$. An oscillating extract, in the presence of replicating DNA, was simulated, with slight modifications, as described before [11]. The total GST-cyclin concentration was set at $300 \mathrm{nM}$, and the $V_{25}$ parameters were decreased to 0.01 (to mimic the effect of vanadate). We assumed that GST-cyclin binds to $\mathrm{Cdc} 2$ with a rate constant $0.001 \mathrm{nM}^{-1} \mathrm{~min}^{-1}$ (which is one-fifth of the normal value). 

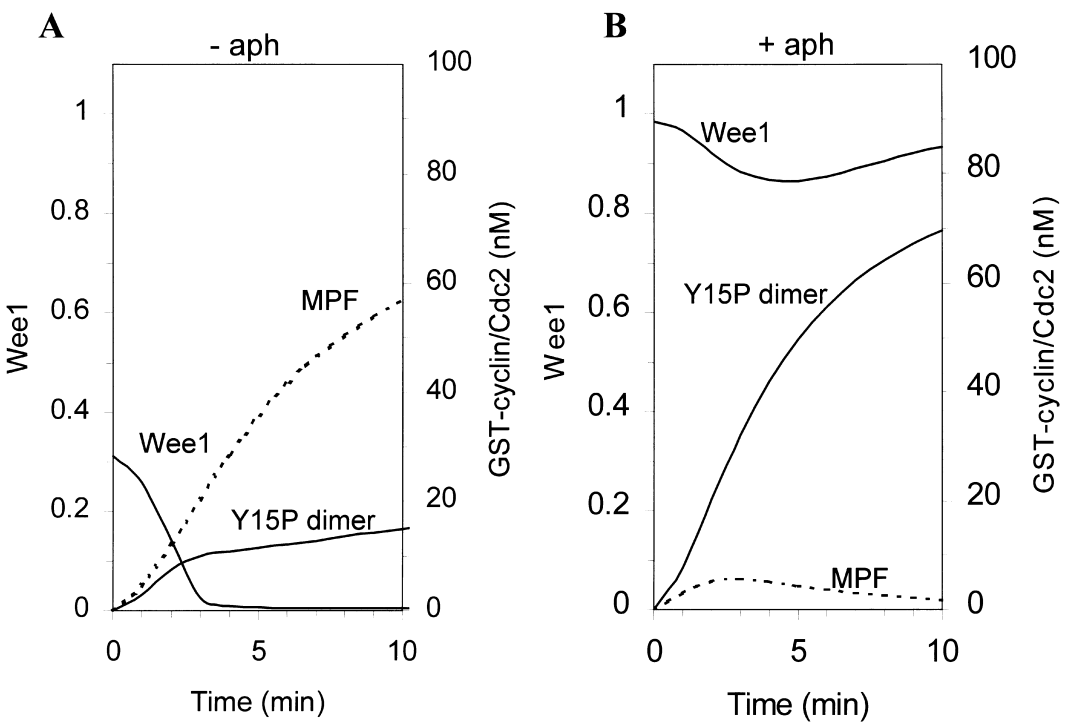

Fig. 6. Unreplicated DNA activates Wee1 in cycling extracts. (A) Extract without DNA. (B) Extract blocked by unreplicated DNA (500 nuclei $/ \mu$ l, plus aphidicolin). Simulation: $[\mathrm{CKI}]_{\mathrm{total}}=0, k_{1}=1 \mathrm{nM} \mathrm{min}{ }^{-1}$. We are simulating the experimental protocol in Fig. 4 of Smythe and Newport [26]. Two oscillating extracts were prepared and, in mid interphase, one was supplemented with unreplicated DNA $\left(k_{\mathrm{wr}}\right.$ and $k_{25 \mathrm{r}}$ increased to $0.76 \mathrm{~min}^{-1}$ in the simulation). Thirty minutes later, GST-cyclin $(300 \mathrm{nM})$ and vanadate were added to both extracts $(t=0$ in the figure). We plot [active Wee1], [active Cdc2/GST-cyclin], and [Y15P-Cdc2/GST-cyclin] over the next 10 min of our simulation. The data in Ref. [26] correspond to the endpoints of the 'Y15P dimer' curve at $t=10$.

experimental results in terms of our original mechanism (Fig. 1A,B), without recourse to a stoichiometric inhibitor mediating the signal from unreplicated DNA. Now we describe an experiment which forces us to introduce an inhibitor with the properties postulated in Fig. 1C.

Cycloheximide blocks extracts in interphase because they cannot synthesize cyclin B. The block can be overridden by adding exogenously synthesized cyclin B, especially with a stable form [20]. An even more potent inducer of mitosis is the AF-Cdc $2 / \Delta c y c B$ (recombinant cyclin B lacking the $\mathrm{N}$-terminal destruction box) complex, for which the inhibitory phosphorylation sites of Cdc2 (Thr-14 and Tyr-15) have been replaced by non-phosphorylable residues (alanine and phenylalanine). Kumagai and Dunphy [10] demonstrated that the mitosis-inducing capacity of AF$\mathrm{Cdc} 2 / \Delta \mathrm{cycB}$ can be abolished or delayed by adding unreplicated DNA to the extract (see Fig. 8, data points). This effect of unreplicated DNA cannot be attributed to its action on Wee1 and Cdc25, because the AF mutant of $\mathrm{Cdc} 2$ is not subject to inhibition by phosphorylation. The simplest explanation is that unreplicated DNA activates a stoichiometric inhibitor
(CKI) of Cdc2/cycB complexes [10]. Small amounts of $\mathrm{AF}-\mathrm{Cdc} 2 / \Delta$ cyclin $\mathrm{B}$ are completely inhibited by the $\mathrm{CKI}$, so mitosis cannot occur in the presence of unreplicated DNA, but larger amounts, exceeding the CKI level, will eventually induce mitosis, after some additional delay.

Fig. 8 shows our simulation of these experiments, assuming that the extract contains $3.5 \mathrm{nM}$ inhibitor. We assume that the inhibitor is inactive when phosphorylated, and that DNA containing active or stalled replication forks induces dephosphorylation (activation) of the inhibitor. This assumption is suggested by the observation of Kumagai and Dunphy [10] that the effect of unreplicated DNA on AF-Cdc2 can be abolished by adding okadaic acid (an inhibitor of type 2 phosphatases) to an extract. In the presence of unreplicated DNA the inhibitor is equally distributed between the phosphorylated and unphosphorylated forms.

In another experiment Kumagai and Dunphy [10] added catalytically inactive AFA-Cdc2/cycB complex (alanine replacing Thr-161, so Cdc2 cannot receive the activatory phosphate group) to aphidicolinblocked extracts to test whether this complex can 

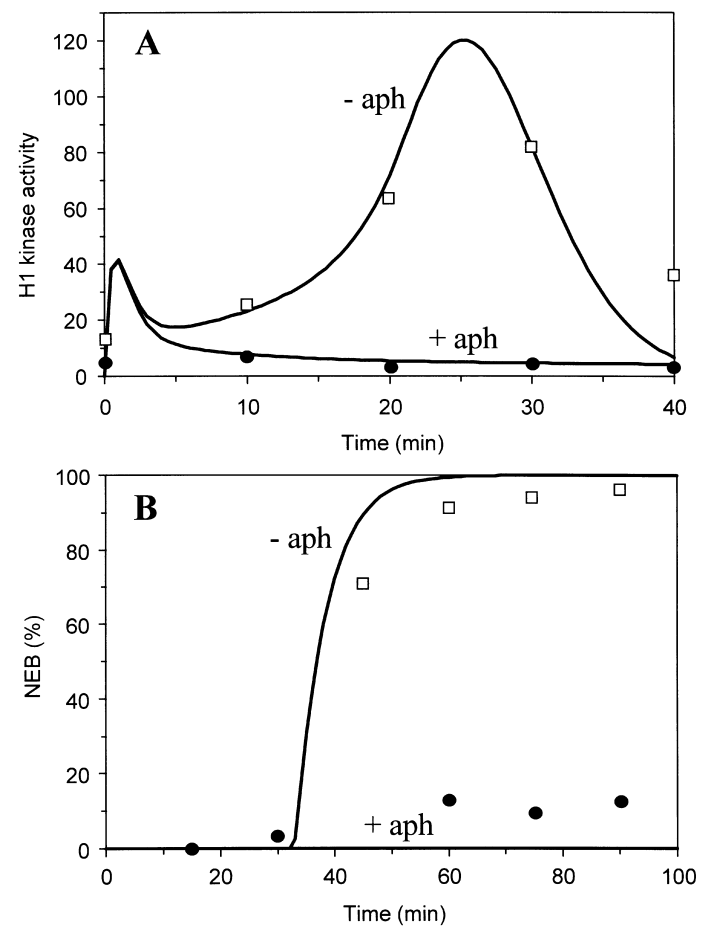

Fig. 7. Unreplicated DNA prevents M-phase induction by MPF in cycloheximide-treated extracts. Data from Fig. 2A,C of Ref. [10]. Extracts were prepared containing 200 nuclei/ $\mu 1$ or 1000 nuclei/ $\mu \mathrm{l}+100 \mu \mathrm{g} / \mathrm{ml}$ aphidicolin. In (A), purified, unphosphorylated $\mathrm{Cdc} 2 /$ cycB complex $(32 \mathrm{nM})$ was added and $\mathrm{H} 1$ kinase activity was followed. In (B), purified non-degradable cyclin B monomer (32 nM) was added and NEB was monitored. Simulation: $[\mathrm{CKI}]_{\text {total }}=0, k_{1}=0 ; k_{\mathrm{wr}}=k_{25 \mathrm{r}}=0.3 \mathrm{~min}^{-1}$ (in presence of unreplicated DNA).

titrate away the putative MPF inhibitor (Fig. 9, data points). In these experiments they used extracts which synthesize cyclin B de novo (not blocked by cycloheximide), and they added 1000 nuclei/ $\mu 1$ to monitor NEB. In these cycling extracts NEB was observed at around $60 \mathrm{~min}$ in the absence of aphidicolin. However, in the presence of aphidicolin, NEB did not occur up to $120 \mathrm{~min}$. Addition of $10 \mathrm{nM}$ AFA-Cdc2/ cycB complex was able to rescue the aphidicolinblocked extract, inducing mitosis at 100 min. Fig. 9 shows our simulation of these experiments, assuming that unreplicated DNA activates the phosphatases working not only on CKI but also on Wee1 and Cdc25.

Notice that, although AFA-Cdc2/cycB releases the block caused by unreplicated DNA, initiation of mitosis is delayed. This delay is attributed to the effect of unreplicated DNA on the phosphatases working on the tyrosine-modifying enzymes. If unreplicated DNA had no effect on these enzymes, then, when AFA-Cdc $2 /$ cycB titrates away the inhibitor and releases the block of mitosis caused by unreplicated DNA, mitosis would occur at the same time (60 min) as without aphidicolin. Therefore we believe that unreplicated DNA works not only through activating a CKI, but also by keeping Wee1 active and Cdc25 inactive.

Once we introduce a CKI into the model, all of our earlier simulations (which assumed $[\mathrm{CKI}]=0$ ) are suspect: would we get the same quantitative agreement with experiments in Figs. 4, 5, 6 and 7 with $[\mathrm{CKI}]=3.5 \mathrm{nM}$ instead of 0 ? All simulations of

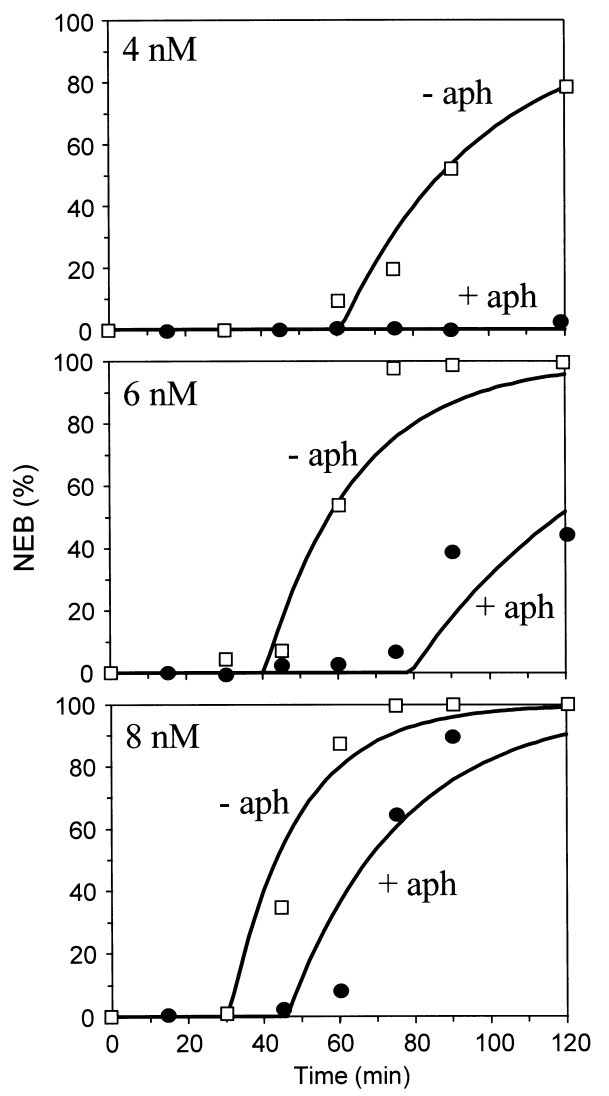

Fig. 8. Unreplicated DNA can block the induction of mitosis by AF-Cdc2/cycB complex. Data from Fig. 8 of Ref. [10]: purified $\mathrm{AF}-\mathrm{Cdc} 2 / \Delta \mathrm{cycB}$ was added at different concentrations $(4,6$ and 8 $\mathrm{nM})$ to interphase extracts containing 200 nuclei/ $\mu \mathrm{l}(\square)$ and 1000 nuclei $/ \mu 1+$ aphidicolin $(\bullet)$, and NEB was followed. Simulations: $[\mathrm{CKI}]_{\text {total }}=3.5 \mathrm{nM}, k_{1}=V_{2}^{\prime}=V_{2}^{\prime \prime}=0 ; k_{\mathrm{wr}}=k_{25 \mathrm{r}}=0.3 \mathrm{~min}^{-1}$ and $k_{\text {ipr }}=0.05 \mathrm{~min}^{-1}$ (in presence of unreplicated DNA). 


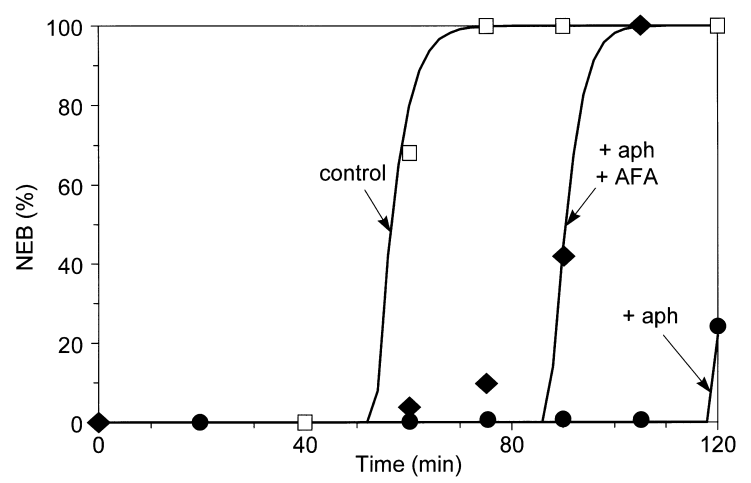

Fig. 9. Catalytically inactive AFA-Cdc2/CycB complex relieves the block of mitosis caused by unreplicated DNA. Data from Fig. 10 of Ref. [10]. NEB was monitored in cycling extracts (lacking cycloheximide, containing 1000 sperm nuclei/ $\mu 1)$. ( $\square)$, control (no further additions); $(\bullet)$, with aphidicolin $(100 \mu \mathrm{g} / \mathrm{ml}) ;(\bullet)$ with AFA-Cdc $2 / \Delta c y c B(10 \mathrm{nM})$ and aphidicolin. Simulation: $[\mathrm{CKI}]_{\text {total }}=3.5 \mathrm{nM}, k_{1}=1 \mathrm{nM} \mathrm{m^{-1 }} ; k_{\mathrm{wr}}=k_{25 \mathrm{r}}=0.28 \mathrm{~min}^{-1}$ and $k_{\text {ipr }}=0.05 \mathrm{~min}^{-1}$ (in presence of unreplicated DNA).

extracts without unreplicated DNA are, of course, unchanged because the CKI in such extracts is phosphorylated and inactive. In the presence of unreplicated DNA, the crucial observations concern the rates of tyrosine phosphorylation and dephosphorylation, and these rates are exactly the same, with or without active CKI, because we assume (see Table 2) that these rate constants are the same for $\mathrm{Cdc} 2 /$ cycB/CKI trimers and $\mathrm{Cdc} 2 /$ cycB dimers. The principal observable effect of the CKI in our model is to raise the cyclin threshold for MPF activation (simulations not shown).

\section{Discussion}

As molecular details of the mitotic control system became clear around 1990, preliminary models based on chemical kinetic equations began to appear. At first the models were simple and gave only a qualitative impression of how the controls might operate $[23,30,31]$. Most models focused on the autonomous, limit-cycle oscillations typical of frog egg embryos and extracts, but Tyson [32] emphasized the equal importance of steady state solutions as representative of checkpoint controls in G2- and M-phases. In 1993 Novak and Tyson [11] presented a comprehensive mechanism of MPF regulation in frog eggs, based on cyclin turnover and tyrosine phosphorylation. The G2 checkpoint for unreplicated DNA was attributed to activation of the phosphatase(s) that activates Wee1 and inhibits Cdc25.

This mechanism for inhibiting MPF by unreplicated DNA was cast in doubt by later observations [10] that unreplicated DNA, added to interphasearrested extracts, causes neither an increase in Wee1 activity nor a decrease in Cdc 25 activity. In this paper we have shown that our original assumption is consistent with these observations. When added to an interphase-arrested extract, unreplicated DNA does not affect Wee1 and Cdc25 initially (they are already fully activated and fully inhibited, respectively). Rather it increases the cyclin threshold for MPF activation.

Recent experiments using mutant forms of $\mathrm{Cdc} 2$ that cannot be inhibited by Tyr-15 phosphorylation show clearly that a CKI must be one of the endpoints of the surveillance mechanism for unreplicated DNA [10]. However, our simulations show equally clearly that this CKI is not the only endpoint. All experimental evidence so far is consistent with the idea that unreplicated DNA, by some signal transduction pathway, affects three regulatory proteins: it activates a CKI, maintains Wee1 active, and maintains Cdc25 inactive. In all cases, the effect of unreplicated DNA is to raise the cyclin threshold for MPF activation. Furthermore, all three effects could be transduced through one (or more) protein phosphatase(s) which remove phosphate groups from Ser and/or Thr residues of Wee1, Cdc25 and the CKI.

Of course, it is possible that the effect of unreplicated DNA on Wee1 and Cdc25 is mediated through some other enzymes besides phosphatases; for example, kinases that phosphorylate Wee1 on 'activating' sites and Cdc25 on 'inhibiting' sites.

Our proposal, that the signal from unreplicated DNA is transduced at least in part through Wee1 and $\mathrm{Cdc} 25$, can be tested directly by measuring the rates of dephosphorylation of these enzymes (by gelshift, as in Ref. [17]) in interphase extracts with and without unreplicated DNA. It can be tested indirectly by measuring the cyclin threshold for MPF activation in interphase extracts with or without unreplicated DNA, and in the presence or absence of AFA$\mathrm{Cdc} 2 / \mathrm{cycB}$ (to titrate the stoichiometric inhibitor induced by unreplicated DNA). If unreplicated DNA 
operates in part through Wee1 and Cdc25, then the cyclin threshold should be raised considerably by adding unreplicated DNA to an interphase extract, and further addition of AFA-Cdc2/cycB may lower the cyclin threshold but will not reduce it to the normal threshold $(20 \mathrm{nM})$ seen in extracts without unreplicated DNA.

The same reasoning we have used to examine the mode of action of unreplicated DNA can be applied to $\mathrm{INH}$, originally characterized as an inhibitor of autocatalytic MPF activation [33]. When INH was identified as a protein phosphatase (type 2A), it was thought to dephosphorylate Thr-161 [34]. Based on the fact that INH increases the MPF activation lag period and the cyclin threshold [20], Novak and Tyson suggested $[11,35]$ that INH must play a role in dephosphorylating Wee1 and Cdc25 as well (because Thr-161 dephosphorylation has only a minor effect on the threshold). Later Lee et al. [36,37] found that INH slows down the CAK-mediated Thr-161 phosphorylation step. They presented evidence that INH does not inhibit Cdc25 activity and does not activate Wee1 activity. For example, by adding a trace of radiolabeled tyrosine-phosphorylated $\mathrm{Cdc} 2 /$ cyclin dimers they were able to follow Tyr-15 dephosphorylation during cyclin-induced MPF activation in the absence and presence of INH (their Fig. 3). Since INH has no influence on tyrosine dephosphorylation rate during the first $10 \mathrm{~min}$, the authors argue that INH does not work by blocking Cdc25 activity.

But this line of reasoning is questionable. Since $\mathrm{Cdc} 25$ is mostly inactive (dephosphorylated) at the beginning of the experiment and during the lag period (first $10 \mathrm{~min}$ ), INH can have no additional effect on Cdc25 activity, even if INH dephosphorylates Cdc25. This explanation is born out by simulations (not shown): whether the only effect of INH is to reduce CAK activity or also to elevate the dephosphorylation of Wee1 and Cdc25, the observed rate of Tyr-15 dephosphorylation is indistinguishable by this experiment. However, the two classes of effects can be resolved if the experiment is carried out for longer incubation time in an undiluted extract. If INH's only effect is to reduce CAK activity, then MPF is eventually activated, after a long delay. But, if INH also dephosphorylates Wee1 and Cdc25, then MPF never activates.

We recognize that this is a difficult paper to under- stand: the experiments are subtle and seemingly contradictory, the models are complex, and the calculations are daunting. Nonetheless, mathematical modeling allows us to think clearly and accurately about control mechanisms in the early embryonic cell cycle. The process of modeling, which forces us to make explicit mechanistic hypotheses, guides and disciplines our biochemical intuition; and, when the model is successful, it shows how all the facts can be brought into a consistent picture. Of course, consistency does not prove that the picture is correct: new facts may force us to modify our mechanism in the future. But for now Tables 1 and 2 represent a thoroughly tested, quantitative model of frog egg extracts, which can serve as a basis for integrating future experimental results with what is already known.

\section{Acknowledgements}

Our research is supported by the National Science Foundations of the USA (MCB-9600536) and Hungary (T-022182 and FKFP0350), and the Howard Hughes Medical Institute (75195-542501). Kathy Chen provided valuable assistance in many stages of this work. Jonathan Moore made several improvements to a preliminary version of this manuscript.

\section{Appendix A Parameter estimation}

Our mathematical model (Table 1) includes 27 rate constants and 16 concentration constants. Table 2 lists the parameter values used in our simulations. Of the six endogenous total concentrations in the model, we know only that $[\mathrm{Cdc} 2]_{\text {total }}=100 \mathrm{nM}$

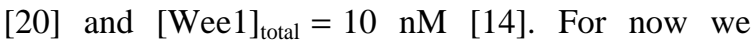
set $[\mathrm{Cdc} 25]_{\text {total }},[\mathrm{Wee}]_{\text {total }},[\mathrm{IE}]_{\text {total }}, \quad[\mathrm{APC}]_{\text {total }}$, and $[\mathrm{Lam}]_{\text {total }}$ to 'one unit' each. When $\mathrm{nM}$ values for all endogenous total concentrations can be specified, all of the rate constants in Table 2 will carry correct dimensions: $\mathrm{nM} \mathrm{min}^{-1}$ (zero order), $\mathrm{min}^{-1}$ (first order), or $\mathrm{nM}^{-1} \min ^{-1}$ (second order).

\section{Appendix A.1 Thr-161 phosphorylation and dephosphorylation}

Kumagai and Dunphy [10] (see their Fig. 6A) 
found no measurable Thr-161 dephosphorylation after $16 \mathrm{~min}$ in interphase extracts; see also Ref. [36]. If more than $90 \%$ of Thr-161-P remains after $16 \mathrm{~min}$, then $k_{\text {cakr }}<\ln (100 / 90) / 16 \mathrm{~min}=0.0066$ $\min ^{-1}$. We set $k_{\text {cakr }}=0.004 \mathrm{~min}^{-1}$ to be safe.

Since Thr-161 dephosphorylation is very slow, Kumagai and Dunphy [10] could estimate the Thr161 phosphorylation directly from their Fig. 5B. They find $47 \%$ Thr-161 phosphorylated after $1 \mathrm{~min}$, so $k_{\text {cak }}=0.64 \mathrm{~min}^{-1}$.

\section{Appendix A.2 Tyr-15 phosphorylation and dephosphorylation}

Kumagai and Dunphy [10] measured the Tyr-15 dephosphorylation rate in $\mathrm{M}$-phase extracts, when all Cdc25 is in the more active form. Their Fig. 4B shows $50 \%$ dephosphorylation after $4 \mathrm{~min}$, which gives $V_{25}{ }^{\prime \prime}=0.174 \mathrm{~min}^{-1}$. Lee et al. [36] also estimated the rate of tyrosine dephosphorylation in mitotic extracts and found a rate constant between 0.052 and $0.061 \mathrm{~min}^{-1}$. Since their extract was 2-fold diluted, these values correspond to $0.1-0.12 \mathrm{~min}^{-1}$ values, which is close to the value we use.

The unphosphorylated form of $\mathrm{Cdc} 25$ is about 10 times less active than the phosphorylated form $[16,17]$. This is consistent with Fig. 4B measurement in Ref. [10], where a drop of phosphotyrosine content to $87 \%$ in $8 \mathrm{~min}$ in interphase extracts was found: $V_{25}{ }^{\prime}=0.017 \mathrm{~min}^{-1}$. The corresponding value in Lee et al. [36] is $0.006-0.009 \mathrm{~min}^{-1}$ (diluted extract) or $0.015 \mathrm{~min}^{-1}$ (undiluted).

Kumagai and Dunphy [10] found that preformed $\mathrm{Cdc} 2 / \mathrm{cycB}$ dimers get fully tyrosinephosphorylated in interphase extracts (see their Fig. 3C) within $2 \mathrm{~min}$, when Weel is in the unphosphorylated, active form. This suggests that the time for half-maximal phosphorylation is less than $1 \mathrm{~min}$. We use a value of $1 \mathrm{~min}^{-1}$ for $V_{\text {wee }}{ }^{\prime \prime}$. This value suggests that Tyr-15 phosphorylation by active Wee1 is slightly faster than Thr-161 phosphorylation by CAK. If this condition were not true then we would get a large peak of MPF after addition of unphosphorylated $\mathrm{Cdc} 2 / \mathrm{cycB}$ dimers to interphase extracts (see Fig. 2C in Ref. [10] and our Fig. 7A).

We assume that the phosphorylated form of Wee1 is 100 times less active $\left(V_{\text {wee }}{ }^{\prime}=0.01 \mathrm{~min}^{-1}\right)$. There is experimental evidence [38] that unphosphorylated Wee 1 is at least 54 times more active than the phosphorylated form (see their Fig. 5). This ratio would give a slightly smaller value than $0.02 \mathrm{~min}^{-1}$ for $V_{\text {wee }}$. However, using a value larger than 0.01 for $V_{\text {wee }}$, we were not able to simulate the experiments (M-phase curve) in Fig. 3B of Ref. [10] (see our Fig. 4).

\section{Appendix A.3 Association of Cdc2 and cyclin}

When Kumagai and Dunphy supplied cycloheximide-arrested extracts with $\Delta$ cyclin B monomers, instead of preformed $\mathrm{Cdc} 2 / \mathrm{cycB}$ dimers, the rate of Tyr-15 phosphorylation was noticeably slower, with a half-life of roughly $2.5 \mathrm{~min}$ (their Fig. 3B). This suggests that the association of cyclin and $\mathrm{Cdc} 2$ monomers is rate-limiting for the two-step process. If $k_{3}[\mathrm{Cdc} 2]_{\text {total }} \ll V_{\text {wee }}$ ", then we would estimate that $k_{3}[\mathrm{Cdc} 2]_{\text {total }}=\ln (2) / 2.5 \mathrm{~min}=0.3 \mathrm{~min}^{-1}$. Actually, for the value of $V_{\text {wee }}$ " we use $\left(1 \mathrm{~min}^{-1}\right), k_{3}[\mathrm{Cdc} 2]_{\text {total }}=$ $0.5 \mathrm{~min}^{-1}$ gives a better fit to the data.

\section{Appendix A.4 Phosphorylation and dephosphorylation of Weel and Cdc25}

We use Michaelis-Menten rate laws to describe the phosphorylation and dephosphorylation of Cdc 25 and Wee1. We assume that $K_{\mathrm{m} 25} \ll[\mathrm{Cdc} 25]_{\text {total }}$, so that $\mathrm{Cdc} 25$ activation by MPF is a highly cooperative transition [39]. Thus, the phosphorylation of $\mathrm{Cdc} 25$ proceeds as a zero order reaction until it is almost complete. Since half-maximal phosphorylation of Cdc25 in M-phase extracts takes about $1 \mathrm{~min}$ (see Fig. 10A in Ref. [17]), we estimate that $k_{25}[\mathrm{MPF}] /$ $[\mathrm{Cdc} 25]_{\text {total }}=0.5 \mathrm{~min}^{-1}$. Estimating that $[\mathrm{MPF}]=25$ $\mathrm{nM}$ in mitosis, we get $k_{25} /[\mathrm{Cdc} 25]_{\text {total }}=0.02 \mathrm{nM}^{-1}$ $\min ^{-1}$. A similar argument can be used to estimate $k_{\mathrm{w}}$ from Fig. 2 in Ref. [38].

The reverse rate constants can be estimated indirectly from the observed cyclin threshold (16 nM nondegradable cyclin, see p. 203 of Ref. [10]) because it depends sensitively on $k_{\mathrm{wr}} / k_{\mathrm{w}}$ and $k_{25} / k_{25}$. We fit the observed thresholds with $k_{\mathrm{w} r} / k_{\mathrm{w}}=k_{25 \mathrm{r}} / k_{25}=5 \mathrm{nM}$. The two ratios are constrained to be the same so that, as MPF activity increases, Wee1 inactivates and Cdc25 activates at the same time; otherwise, the phosphorylation state of Tyr-15 would show very strange fluctuations which are never observed. 


\section{Appendix A.5 Cyclin synthesis and degradation}

The rate constant for cyclin synthesis, $k_{1}$, may vary considerably from one preparation to another, depending on how much cyclin mRNA is present in the extract, and whether cycloheximide is added. $k_{1}=1$ $\mathrm{nM} \min ^{-1}$ is a typical value.

The half-life of cyclin at the end of mitosis is less than 5 min (see Fig. 1 in Ref. [22]), so we set $V_{2}^{\prime \prime}$ to $\ln (2) / 2.8 \mathrm{~min}=0.25 \mathrm{~min}^{-1}$. In an interphase extract, Jones and Smythe [40] observed that $25-30 \%$ of cyclin B1 is degraded in $110 \mathrm{~min}$, giving a half-life of $240 \mathrm{~min}$. We assume a shorter half-life $(140 \mathrm{~min}$, $\left.V_{2}^{\prime}=0.005 \mathrm{~min}^{-1}\right)$. Simulations with a smaller value of $V_{2}^{\prime}\left(0.001 \mathrm{~min}^{-1}\right)$ showed no significant differences.

\section{Appendix A.6 Other parameters}

The rate constants and Michaelis constants that characterize IE and APC are conjectural for the most part (in fact, IE itself is a hypothetical component). We choose $K_{\text {mie }}$ and $K_{\text {mier }}$ both $\ll 1$, so that IE functions as an 'ultrasensitive switch' [39] that converts an 'analog signal' from MPF into a 'digital signal': $[\mathrm{IE}]=0$ or 1 . The switch-over point occurs at an MPF level given by $k_{\text {ier }} / k_{\text {ie }}=7.5 \mathrm{nM}$. In order for the extract to show spontaneous MPF oscillations, this switch-over point cannot be much smaller or much larger; also, this value is consistent with the MPF threshold for APC activation observed by Felix et al. [22]. So we have some confidence in the ratio $k_{\mathrm{ier}} / k_{\mathrm{ie}}$. We choose the rates to be relatively fast, so that IE responds quickly to MPF, to be consistent with the observation of Felix et al. [22] that the lag from MPF addition to maximal rate of cyclin degradation saturates quickly with increasing amount of MPF. The minimal lag time (approximately $7 \mathrm{~min}$ ) determines the rate constant for APC activation: $k_{\mathrm{ap}} \approx 0.13 \mathrm{~min}^{-1}$. The other three parameters $\left(k_{\text {apr }}, K_{\text {map }}, K_{\text {mapr }}\right)$ are chosen to give a desirable response of APC activity to increasing and decreasing IE activity as the cell exits mitosis.

Ultrasensitivity of the switches in the cyclin degradation pathway favors large amplitude oscillations in total cyclin level [44]. On the other hand, ultrasensitivity is not necessary for oscillation in MPF activity driven by tyrosine phosphorylation (notice that the
$K_{\mathrm{m}}$ values for regulation of Wee1 and $\mathrm{Cdc} 25$ are not as small as those for IE and APC). We have not studied thoroughly how the properties of our model depend on the relative magnitudes of these Michaelis constants. The values we have chosen are convenient for our simulations, but there exist, at present, little kinetic data to assess the validity of our assumptions in this part of the model.

Thus, of the 27 parameters describing our core model (Fig. 1A,B), more than half can be reliably estimated from kinetic data in the literature. Eight of the remaining parameters are Michaelis constants which determine the 'shape' of the sigmoidal functions describing how Wee1, Cdc25, IE and APC are turned on and off by post-translational modification. There are no direct measurements of these shapes, so it is impossible to estimate these parameters at present. We assign nominal values to these Michaelis constants, to generate shapes that are convenient for our simulations.

There are two other groups of parameter values in Table 2, for inhibitor (CKI) and NEB, but they are not essential to our core model of the frog egg cell cycle, so we will not try to justify them any further than our simulations warrant.

\section{References}

[1] A. Murray, T. Hunt, The Cell Cycle, W.H. Freeman, New York, 1993.

[2] J. Gerhart, M. Wu, M. Kirschner, J. Cell Biol. 98 (1984) 1247.

[3] J. Newport, M. Kirschner, Cell 30 (1982) 687.

[4] M. Dasso, J.W. Newport, Cell 61 (1990) 811.

[5] J. Minshull, H. Sun, N. Tonks, A. Murray, Cell 79 (1994) 475.

[6] J. Tyson, B. Novak, G. Odell, K. Chen, C. Thron, Trends Biochem. Sci. 21 (1996) 89.

[7] P. Nurse, Nature 344 (1990) 503.

[8] D.O. Morgan, Nature 374 (1995) 131.

[9] M. Dasso, C. Smythe, K. Milarski, S. Kornbluth, J.W. Newport, in: J. Marsh (Ed.), Regulation of the Eukaryotic Cell Cycle, Wiley, Chichester, 1992, p. 161.

[10] A. Kumagai, W.G. Dunphy, Mol. Biol. Cell 6 (1995) 199.

[11] B. Novak, J.J. Tyson, J. Cell Sci. 106 (1993) 1153.

[12] A. Murray, Cell 81 (1995) 149.

[13] M. Solomon, Trends Biochem. Sci. 19 (1994) 496.

[14] P.R. Mueller, T.R. Coleman, W.G. Dunphy, Mol. Biol. Cell 6 (1995) 119.

[15] P.R. Mueller, T.R. Coleman, A. Kumagai, W.G. Dunphy, Science 270 (1995) 86. 
[16] T. Izumi, D.H. Walker, J.L. Maller, Mol. Biol. Cell 3 (1992) 927.

[17] A. Kumagai, W.G. Dunphy, Cell 70 (1992) 139.

[18] T. Izumi, J.L. Maller, Mol. Biol. Cell 6 (1995) 215.

[19] A. Kumagai, W.G. Dunphy, Science 273 (1996) 1377.

[20] M.J. Solomon, M. Glotzer, T.H. Lee, M. Philippe, M.W. Kirschner, Cell 63 (1990) 1013.

[21] A.W. Murray, M.W. Kirschner, Nature 339 (1989) 275

[22] M.A. Felix, J.C. Labbe, M. Doree, T. Hunt, E. Karsenti, Nature 346 (1990) 379.

[23] A. Goldbeter, Proc. Natl. Acad. Sci. USA 88 (1991) 9107.

[24] J.E.Ferrell Jr., , M. Wu, J.C. Gerhart, G.S. Martin, Mol. Cell. Biol. 11 (1991) 1965

[25] J. Newport, M. Dasso, J. Cell Sci. Suppl. 12 (1989) 149.

[26] C. Smythe, J.W. Newport, Cell 68 (1992) 787.

[27] D.H. Walker, A.A. DePaoli-Roach, J.L. Maller, Mol. Biol. Cell 3 (1992) 687.

[28] P.R. Clarke, I. Hoffmann, G. Draetta, E. Karsenti, Mol. Biol. Cell 4 (1993) 397

[29] P.R. Clarke, D. Leiss, M. Pagano, E. Karsenti, EMBO J. 11 (1992) 1751

[30] C. Hyver, H. Le Guyader, BioSystems 24 (1990) 85.
[31] R. Norel, Z. Agur, Science 251 (1991) 1076.

[32] J.J. Tyson, Proc. Natl. Acad. Sci. USA 88 (1991) 7328

[33] M.S. Cyert, M.W. Kirschner, Cell 53 (1988) 185.

[34] T.H. Lee, M.J. Solomon, M.C. Mumby, M.W. Kirschner, Cell 64 (1991) 415.

[35] B. Novak, J.J. Tyson, J. Theor. Biol. 165 (1993) 101.

[36] T.H. Lee, C. Turck, M.W. Kirschner, Mol. Biol. Cell 5 (1994) 323.

[37] T.H. Lee, Sem. Cancer Biol. 6 (1995) 203

[38] Z.H. Tang, T.R. Coleman, W.G. Dunphy, EMBO J. 12 (1993) 3427.

[39] A. Goldbeter, D.E. Koshland Jr., Proc. Natl. Acad. Sci. USA 78 (1981) 6840.

[40] C. Jones, C. Smythe, J. Cell Sci. 109 (1996) 1071.

[41] B. Ermentrout, PhasePlane The Dynamical Systems Tool, Version 3.0, Brooks/Cole, Pacific Grove CA, 1990.

[42] P. Gallant, A.M. Fry, E.A. Nigg, J. Cell Sci. Suppl. 19 (1995) 21.

[43] E.A. Nigg, BioEssays 17 (1995) 471.

[44] A. Goldbeter, J.-M. Guilmot, J. Phys. Chem. 100 (1996) 19174. 